\title{
Intralesional injection of Rose Bengal augments the efficacy of gemcitabine chemotherapy against pancreatic tumors
}

\author{
Patrick Innamarato \\ Moffitt Cancer Center \\ Jennifer Morse \\ Moffitt Cancer Center
}

Amy Mackay

Moffitt Cancer Center

Sarah Asby

Moffitt Cancer Center

Matthew Beatty

Moffitt Cancer Center

Jamie Blauvelt

Moffitt Cancer Center

Scott Kidd

Moffitt Cancer Center

John Mullinax

Moffitt Cancer Center

Amod Sarnaik

Moffitt Cancer Center

Shari Pilon-Thomas ( $\sim$ shari.pilon-thomas@moffitt.org )

Moffitt Cancer Center

\section{Research Article}

Keywords: ovalbumin, neoantigen, OVA, HMGB1, S100A8, IL-1a

Posted Date: January 13th, 2021

DOI: https://doi.org/10.21203/rs.3.rs-140621/v1

License: (c) (i) This work is licensed under a Creative Commons Attribution 4.0 International License.

Read Full License 


\section{Abstract \\ Background}

Chemotherapy regimens that include the utilization of gemcitabine are the standard of care in pancreatic cancer patients. However, most patients with advanced pancreatic cancer die within the first 2 years after diagnosis, even if treated with standard of care chemotherapy. This study aims to explore combination therapies that boost the efficacy of standard of care regimens in pancreatic cancer patients.

\section{Methods}

In this study, we used PV-10, a 10\% solution of rose bengal, to induce the death of human pancreatic tumor cells in vitro. Murine in vivo studies were carried out to examine the effectiveness of the direct injection of PV-10 into syngeneic pancreatic tumor cells in causing lesion-specific ablation. Intralesional PV-10 treatment was combined with systemic gemcitabine treatment in tumor-bearing mice to investigate the control of growth among treated tumors and distal untreated tumors. The involvement of the immune-mediated clearance of tumors was examined in immunogenic tumor models that express ovalbumin (OVA).

\section{Results}

In this study, we demonstrate that the injection of PV-10 into mouse pancreatic tumors caused lesionspecific ablation. We show that the combination of intralesional PV-10 with the systemic administration of gemcitabine caused lesion-specific ablation and delayed the growth of untreated distal tumors. We observed that this treatment strategy was markedly more successful in immunogenic tumors that express the neoantigen, OVA, suggesting that the combination therapy enhanced the immune clearance of tumors. Moreover, the regression of tumors in mice that received PV-10 in combination with gemcitabine was associated with the depletion of splenic $\mathrm{CD} 11 \mathrm{~b}^{+} \mathrm{Gr}-1^{+}$cells and increases in damage associated molecular patterns HMGB1, S100A8, and IL-1a.

\section{Conclusions}

These results demonstrate that intralesional therapy with PV-10 can enhance the efficacy gemcitabine against pancreatic tumors.

\section{Introduction}

The intralesional injection of PV-10 can induce the destruction of locally treated tumors and simultaneously induce a systemic immune response that promotes the regression of distal, untreated tumors[1, 2]. PV-10 is a solution of the xanthene dye, rose bengal disodium that is currently being 
investigated in multiple clinical trials as an anti-cancer agent for multiple malignancies including cutaneous melanoma (NCT02557321) and metastatic liver cancer (NCT00986661)[3, 4].

Previous reports from our group have demonstrated that the direct injection of PV-10 into murine melanoma tumors can completely eliminate treated lesions, but also promote the regression of uninjected bystander lesions in the skin and lungs[1]. We demonstrated that the release of the damage associated molecular pattern (DAMP), high mobility group box 1 (HMGB1), from PV-10 treated tumors induced the activation of dendritic cells (DCs) which subsequently primed anti-tumor T cell responses in lymph nodes. Moreover, treatment with PV-10 in melanoma patients resulted in increased levels of HMGB1 in the serum, which was associated with improved anti-tumor activity of circulating T cells. Thus, in addition to its direct ablative properties, $\mathrm{PV}-10$ is effective at inducing DAMP release from tumors which can augment anti-tumor immune responses.

The clearance of tumors after treatment with radiotherapy and chemotherapy agents is dependent on the induction of immunogenic cell death and the release of DAMPs[5]. However, the immunologic consequences of DAMP release can have disparate effects on anti-tumor immunity. Indeed, HMGB1 promotes the cross-presentation activity of DCs required for T cell priming[6]. Yet, HMGB1 also promotes the accumulation and immunosuppressive capacity of myeloid derived suppressor cells (MDSCs)[7, 8]. Similarly, the DAMP, heat shock protein 70 (Hsp70) can prevent the translocation of peptide-major histocompatibility complexes (pMHC) and promote the production of interleukin 10 (IL-10), which subsequently suppresses anti-tumor T cell responses[9, 10]. In contrast, Hsp70 also promotes natural killer (NK) cell-mediated cytotoxicity of tumor cells [11]. Thus, the characterization of the DAMP release and its effects on the immune system are necessary to understand therapeutic responses to anti-cancer agents.

Despite the marked improvement in therapeutic options for development of multiple tumor types over the past decade, pancreatic cancer has remained difficult to treat and only $4 \%$ of patients live beyond 5 years after their initial diagnosis[12-14]. Furthermore, frontline treatments that include the utilization of gemcitabine have short-term benefits, but ultimately lead to chemoresistance and disease progression[15-18]. The robust therapeutic resistance of pancreatic cancer is due in part to the architecture of the tumor and the frequency of disseminated disease at the time of clinical presentation. For instance, the pancreatic tumor stroma can promote $T$ cell exclusion and also harbors a highly immunosuppressive microenvironment, which induces T cell dysfunction[19-22]. Moreover, tumorinfiltrating $T$ cells are localize to stroma elements of tumors and are spatially distant from pancreatic tumor cells[23]. Thus, it is imperative to develop new therapeutic strategies to augment standard of care practices with a goal of promoting anti-tumor immunity against local and distant pancreatic tumors.

In this study, we investigated the efficacy of intralesional (i.I.) PV-10 treatment in combination with gemcitabine in pancreatic tumor models. We demonstrate that PV-10 can effectively augment the efficacy of gemcitabine against murine pancreatic tumors. 


\section{Results}

\section{PV-10 kills pancreatic tumor cells in vitro}

We first determined whether PV-10 could effectively kill pancreatic tumor cells. We cultured murine Panc02 tumor cells with varying concentrations of PV-10 for 24hrs and determined that a concentration of $200 \mu \mathrm{M}$ was the most effective at inducing cell death as determined by Annexin-V and DAPI positivity (Fig. 1A). We next cultured a panel of human pancreatic tumor cell lines (CFPAC1, MiaPaca2, Panc-1, and SU8686) and murine Panc02 in media without PV-10, $50 \mu \mathrm{M}$ PV-10, or $200 \mu \mathrm{M}$ PV-10. We found that $200 \mu \mathrm{M}$ PV-10 was highly effective at inducing cell death as indicated by Annexin-V and DAPI doublepositive cells, albeit the frequency of dead cells varied amongst individual tumor cell lines. Similarly, the frequency of live cells (Annexin- $\left.V^{-} D A P I\right)$ were decreased in all tested tumor cell lines after treatment with $200 \mu \mathrm{M}$ PV-10. Moreover, PV-10 modestly increased the frequency of Annexin- $\mathrm{V}^{+} \mathrm{DAPI}^{-}$and Annexin$\mathrm{V}^{-} \mathrm{DAPI}^{+}$cells in some tumor cell lines. Additionally, the $50 \mu \mathrm{M}$ PV-10 increased cell death compared to untreated tumor cells, but at a lower rate in comparison to cells treated with $200 \mu \mathrm{M} \mathrm{PV-10} \mathrm{(Fig.} \mathrm{1B-E).}$

We next determined that the saturation of PV-10 in tumor cells was associated with increased cell death. Rose bengal excites at $525 \mathrm{~nm}$ and emits a fluorescent signal at $570 \mathrm{~nm}$ which allowed us to assess tumor cell uptake of PV-10. Notably, the staining intensity corresponded to the frequency of dead cells. We observed that the frequency of dead Panc- 1 cells increased after treatment with $200 \mu \mathrm{M} \mathrm{PV-10}$ and that the staining intensity was higher in comparison to Panc-1 cells treated with $50 \mu \mathrm{M} \mathrm{PV-10} \mathrm{(Fig.} \mathrm{2A).} \mathrm{In}$ cells treated with $50 \mu \mathrm{M}$ PV-10, we identified two distinct populations of tumor cells that had differing intensities of PV-10 staining and uptake (PV-10 high and PV-10 low). In most tumor cells lines, the frequency of live cells was significantly reduced in $\mathrm{PV}-10^{\text {high }}$ tumor cells in comparison to $\mathrm{PV}-10^{\text {low }}$ cells. Moreover, dead cells were almost exclusively contained within the PV-10 high population (Fig. 2B-D). Together, these data demonstrate that PV-10 can effectively kill human and murine pancreatic tumor cells.

\section{In vivo efficacy of intralesional PV-10 against murine pancreatic tumors}

First, we evaluated whether the release of DAMPs could be associated with tumor regressions in response to PV-10 treatment. TLR4 is a receptor for lipopolysaccharide (LPS), but also for the DAMP, HMGB1. We used a reporter cell line to assess the activation of TLR4. Serum was collected from PV-10 treated mice or control PBS treated mice 24hrs after intralesional (i.I.) injection and cultured with HEK-Blue mTLR4 cells overnight. TLR4 reporter activity was increased in cells exposed to serum from PV-10 treated mice (Fig. 3A). Likewise, the abundance of HMGB1 was increased in the serum of mice 24 hours after PV-10 treatment, suggesting that HMGB1 could activate TLR4 in PV-10 treated mice (Fig. 3B). Next, we assessed the activity of PV-10 in a bilateral model in mice with Panc02 tumors. One tumor was treated with i.I. PBS or PV-10, while the tumor on the opposite flank was left untreated. PV-10 slowed tumor growth in treated tumors but had no effect on bystander uninjected tumors (Fig. 3C-D). 
Figure 3. Effect of PV-10 against murine Panc02 tumors in vivo. (A) Serum collected from mice treated with i.I. PBS or i.I. PV-10 were collected 24hrs after treatment. Serum was cultured with HEKBlue-mTLR4 reporter cells overnight. (B) HMGB1 in the sera of mice treated with i.I. PBS or i.I. PV-10. (C) Tumor growth of treated tumors with i.I. PBS or i.I. PV-10. (D) Tumor growth of uninjected tumors implanted on the opposite flank of mice.

\section{Gemcitabine treatment is enhanced by intralesional PV-10}

PV-10 effectively delayed tumor growth after i.I. injection into Panc02 tumors but did not promote a systemic immune response that could elicit anti-tumor activity in uninjected tumors. We hypothesized that the PV-10 would effectively induce a systemic immune response to pancreatic tumor cells that expressed a highly immunogenic antigen. In mice with a single Panc02 tumor expressing the ovalbumin (OVA) protein, we found that i.I. treatment with PV-10 was as effective as treatment with systemic gemcitabine or the combination of i.I. PV-10 and gemcitabine (Fig. 4A). However, in a bilateral tumor model gemcitabine treatment alone failed to reduce tumor growth in either lesion, suggesting that the increased tumor burden dampened the efficacy of the chemotherapy. In contrast, i.l. PV-10 treatment alone and the combination of i.I. PV-10 with systemic gemcitabine induced the complete regression in $50 \%$ and $62.5 \%$ of treated tumors respectively (Fig. 4B). In uninjected bystander tumors, tumor growth was effectively delayed in mice that received i.I. PV-10 in one lesion in combination with systemic gemcitabine (Fig. 4C). Together, these data suggest that tumor burden and the immunogenicity of pancreatic tumors affect the efficacy of combinatorial i.I. PV-10 and systemic gemcitabine.

In a single-flank model in mice with Panc02 tumors, we observed that i.I. PV-10 alone delayed tumor growth in a subset of mice in comparison to mice that received i.I. PBS. Moreover, systemic gemcitabine delayed tumor growth, but the combination of i.I. PV-10 with systemic gemcitabine was the most effective at delaying tumor growth (Fig. 5A-B). Next, we harvested tumors at the termination of the experiment and confirmed that mice treated with i.I. PBS and systemic gemcitabine had smaller tumors in comparison to mice that received i.I. PBS alone or PV-10 alone. Moreover, tumors were significantly smaller in mice that received the combination treatment of PV-10 with systemic gemcitabine (Fig. 5C). Thus, these data demonstrate that i.I. PV-10 enhances the efficacy of systemic gemcitabine treatment.

Figure 5. Combination therapy with PV-10 and gemcitabine induces tumor regression. (A) Individual tumor growth curves in mice that received i.I. PBS (top left), i.I. PV-10 (top right), i.l. PBS + i.p. Gem (bottom left), i.l. PV-10 + i.p. Gem (bottom right). (B) Summary of tumor growth curves from (A) $(n=6-8$ per group). Data are representative of 2 independent experiments (C) The mass of tumors at the termination of the experiment. Data are a compilation of 2 independent experiments. $(n=16-17$ per group).

\section{Systemic effects of PV-10 and gemcitabine}

Next, we wanted to identify correlates that could explain the enhanced anti-tumor effect of gemcitabine when combined with PV- 10 . We analyzed the frequency of immune cells within the spleens of mice that received i.I. PV-10 and/or gemcitabine. We identified that the frequency of CD4 or CD8 T cells were 
unchanged by either PV-10 or gemcitabine (Fig. 6A). In contrast, gemcitabine effectively reduced the frequency of total $C D 11 b^{+}$myeloid cells in mice that received combination treatment with i.I. PBS or i.I. PV-10 (Fig. 6B). Specifically, gemcitabine reduced the frequency of Gr-1 ${ }^{+}$cells, while Gr-1- ${ }^{-}$cells comprised a higher proportion of myeloid cells in mice that received gemcitabine (Fig. $6 \mathrm{C}$ ). Next, we examined the abundance of DAMPs in the serum of mice 9 days after receiving treatment. We identified that S100A8, IL-1a, and HMGB1 were only elevated in mice that received both i.I. PV-10 and gemcitabine (Fig. 7A, C-D); S100A9 and Hsp70 was not significantly altered by PV-10 or gemcitabine (Fig. 7B, E). Furthermore, these DAMPs were only elevated in mice that received both i.I. PV-10 and gemcitabine. Thus, the enhanced antitumor activity of combinatorial i.I. PV-10 with systemic gemcitabine is associated with reduced CD11 ${ }^{+}$Gr- $1^{+}$cells and increased S100A8, IL-1a, and HMGB1.

\section{Discussion}

Combination therapy strategies with gemcitabine have often failed to improve the survival in patients with pancreatic cancer[15-18]. Notably, the addition of nab-paclitaxel has increased the survival of pancreatic cancer patients when treatment is combined with gemcitabine. However, the 2-year survival rate in patients that receive nab-paclitaxel plus gemcitabine is approximately $9 \%$ in comparison to $4 \%$ who received gemcitabine alone[18]. Thus, there is a potent need to define therapeutic combinations that enhance the durability of clinical responses that ultimately extend the survival of pancreatic cancer patients. With the results described in this study, we believe that it is feasible to combine intralesional therapy with PV-10 with standard of care chemotherapy. We provide evidence that the potentiation of anti-tumor immune responses is necessary for profound tumor growth stabilization and regression. Specifically, treated Panc02 tumors were controlled upon i.I. therapy with PV-10, but untreated bystander tumors were unaffected (Fig. 3C-D). In contrast, in Panc02 tumors that express that immunogenic neoantigen, OVA, we observed that monotherapy with gemcitabine or PV-10 was equally as effective at controlling tumor growth in a single flank model (Fig. 4A). Moreover, PV-10 treatment alone or in combination with gemcitabine was capable of inducing the complete regression of treated tumors, while gemcitabine monotherapy failed to induce complete regressions. This was in contrast to the effectiveness of gemcitabine monotherapy in mice bearing a single Panc020VA tumor. This suggests that the increased tumor burden in mice with lesions on both flanks diminished the efficacy of gemcitabine, which was overcome when combined with i.I. PV-10. In addition, the rate of tumor growth of untreated bystander tumors was slowed in mice that received PV-10 in combination with gemcitabine versus gemcitabine alone (Fig. 4B-C). This suggests that an immunogenic antigen potentiates the combination of PV-10 and gemcitabine which results in the regression of local and distally untreated tumors.

We next examined the efficacy of PV-10 combination therapy in Panc02 tumors that did not express OVA. We observed that PV-10 treatment alone had a modest effect in reducing tumor growth. Indeed, gemcitabine monotherapy effectively reduced tumor growth. However, the reduction of tumor growth was enhanced in mice that received combination therapy with PV-10 and gemcitabine (Fig. 5). Despite that 
Panc02 tumors are less immunogenic than Panc020VA tumors, we were able to observe a significant improvement in tumor growth control and regression in mice that received combination therapy. Thus, the combination of gemcitabine with PV-10 can induce tumor regression even in less immunogenic tumors.

Treatment with gemcitabine is associated with the depletion of MDSCs and the promotion of tumoricidal activity by tumor-associated macrophages[24, 25]. Indeed, we observed that gemcitabine effectively reduced the frequency of bulk $C D 11 b^{+}$myeloid cells within spleens. However, there was a proportional shift characterized by the reduction of $C D 11 b^{+} G r-1^{+}$MDSCs and an increase in CD $11 b^{+} G r-1^{-}$myeloid cells. This reduction of MDSCs was ultimately associated with reduced tumor growth in mice that received gemcitabine alone or the combination with PV-10. We further investigated systemic changes that could impact the immune system in response to PV-10 treatment. Indeed, PV-10 treatment alone increased the abundance of HMGB1 within 24hrs after injection (Fig. 3B). We and others have shown that HMGB1 is an important mediator of DC activation and promotion of anti-tumor immunity[1, 6, 26]. Intriguingly, the increased abundance of HMGB1 and other DAMPs persisted in mice that received PV-10 in combination with gemcitabine (Fig. 7). Specifically, we observed that HMGB1, S100A8, and IL-1a were increased 9 days after treatment in mice that received PV-10 in combination with gemcitabine. Notably, mice that received the combination therapy exhibited the greatest reduction in tumor growth amongst all experimental groups, suggesting that the increased abundance of DAMPs in circulation is associated with better therapeutic responses. While HMGB1 can promote anti-tumor immune responses, it can simultaneously potentiate tumor cell survival mechanisms[27, 28]. Similarly, S100 proteins and IL-1a appear to have important roles in promoting pancreatic tumor progression. For instance, S100A8 and S100A9 enhances the production of IL-8 in pancreatic tumor cells which could promote the accumulation of immunosuppressive myeloid cells, including MDSCs[29-31]. Meanwhile, IL-1a can enhance the metastatic potential of pancreatic tumor cells by maintaining the constitutive activation of nuclear factor к-B (NFKB) and promoting the secretion of hepatocyte growth factor (HGF)[32, 33]. Despite the roles of these DAMPs in promoting pancreatic tumor progression, we observed that the increase of these factors was associated with tumor regression in mouse models. Hence, the specific roles of DAMPs that are released by pancreatic tumors after PV-10 treatment remain unclear. Future studies will address the immunological consequences of these DAMPs on promoting anti-tumor immunity in the context of pancreatic cancer.

In conclusion, we demonstrate that intralesional therapy with PV-10 is a feasible strategy to augment therapeutic responses when combined with gemcitabine. Together, the results of this study provide support for future studies to investigate the induction of systemic anti-tumor immune responses after PV10 treatment.

\section{Methods}

\section{Cell lines and cell culture}


Panc02 pancreatic cancer (obtained from ATCC), were cultured in RPMI media supplemented with 10\% heat-inactivated FBS, $0.1 \mathrm{mM}$ nonessential amino acids, $1 \mathrm{mM}$ sodium pyruvate, $2 \mathrm{mM}$ fresh L-glutamine, $100 \mathrm{mg} / \mathrm{ml}$ streptomycin, $100 \mathrm{U} / \mathrm{ml}$ penicillin, $50 \mathrm{mg} / \mathrm{ml}$ gentamicin, $0.5 \mathrm{mg} / \mathrm{ml}$ fungizone (all from Life Technologies, Rockville, MD), and 0.05 mM 2-ME (Sigma-Aldrich, St. Louis, MO). To generate the ovalbumin (OVA) expressing fluorescent Panc02 cell line, cells were exposed to supernatants containing a lentiviral vector comprised of a fluorescent ZsGreen (ZsG) protein and OVA. Upon successful transfection, ZsGreen ${ }^{\text {hi }}$ tumor cells were subjected to FACS using BD FACSAria. OVA-ZsGreen ${ }^{\text {hi }}$ tumor cells were passaged in vitro 4 times whereby OVA expression was validated by staining for $\mathrm{H} 2-\mathrm{K}^{\mathrm{b}}$ bound to SIINFEKL peptide (25-D1.16, BioLegend). CFPAC1, MiaPaca2, Panc-1, and SU8686 cells (obtained from ATCC) were grown and maintained in culture according to supplier guidelines. The cell lines tested negative for mycoplasma contamination. All cell lines were passaged less than 10 times after initial revival from frozen stocks. All cell lines were authenticated using STR profiling in 2018.

\section{Apoptosis and cell death detection}

Human and murine pancreatic tumor cells were cultured in 12 well plates and grown to $\sim 60 \%$ confluency. Then, the indicated concentrations of PV-10 were added to media and cells were cultured for $24 \mathrm{hrs}$. Adherent cells were collected by gentle scraping and pooled with non-adherent cells. Cells were washed 3 times in PBS to remove excess PV-10. Washed cells were then stained with Annexin-V APC and DAPI (both from BioLegend) and analyzed on a BD FACSCelesta to determine the frequency of apoptotic and dead cells.

\section{Mouse models and treatment}

Female C57BL/ 6 mice (6-8 weeks old) were purchased from Charles River Laboratories. Animal studies were carried out in compliance with ARRIVE guidelines. Mice were randomized before and after tumor implantation when put onto a study that included drug treatment. Panc02 and Panc02OVA-ZsGreen tumor cells $\left(5 \times 10^{4}\right)$ were implanted subcutaneously into one flank of a mouse to establish a single tumor. To establish a bilateral tumor model, tumor cells were implanted in the opposite flanks. On day 7, a single tumor was treated with intralesional PV-10. Investigators could not be blinded to mice that received PV-10 due to the red staining of the tumor tissue and surrounding skin that was apparent within days after injection. Gemcitabine ( $60 \mathrm{mg} / \mathrm{kg}$ ) was injected intraperitoneally twice per week for 2 weeks. Mice were housed at the Animal Research Facility of the $\mathrm{H}$. Lee Moffitt Cancer Center and Research Institute. Tumor growth measurement studies were concluded when $>30 \%$ of an experimental group was found dead or required humane euthanization. Mice were humanely euthanized by $\mathrm{CO}_{2}$ inhalation and cervical dislocation according to the American Veterinary Medical Association Guidelines. Mice were observed daily and were humanely euthanized if a solitary subcutaneous tumor exceeded $300 \mathrm{~mm}^{2}$ in area, evidence of ulceration, or mice showed signs referable to metastatic cancer. All animal experiments were approved by the Institutional Animal Care and Use Committee and performed in accordance with the U.S. Public Health Service policy and National Research Council guidelines.

\section{Detection of DAMPs in mouse serum}


Blood was collected at the termination of experiments. Blood specimens were centrifuged at 2000xg for 10 minutes at room temperature to separate serum from other blood content. The abundance of HMGB1 was determined by HMGB1 ELISA (IBL International); HSP70 and IL-1a were determined by Human/Mouse/Rat Total HSP70/HSPA1A DuoSet IC ELISA and Mouse IL-1 alpha/IL-1F1 Quantikine ELISA Kit (both from R\&D Systems, a Biotechne brand); S100A8 and S100A9 were determined by Mouse Magnetic Luminex Assay (R\&D Systems, a Biotechne brand) and analyzed on the Luminex 100 (LuminexCorp).

\section{Assessment of TLR4 activity by HEK-Blue mTLR4 reporter cell line}

Cryopreserved HEK-Blue mTLR4 cells (InvivoGen) were thawed, washed with pre-warmed medium (DMEM, $4.5 \mathrm{~g} / \mathrm{I}$ glucose, 10\% (v/v) FBS, 100U/mL penicillin, $100 \mu \mathrm{g} / \mathrm{mL}$ streptomycin, $100 \mu \mathrm{g} / \mathrm{mL}$ Normocin, $2 \mathrm{mM} \mathrm{L-Glutamine)} \mathrm{and} \mathrm{then} \mathrm{transferred} \mathrm{to} \mathrm{a} 25 \mathrm{~cm}^{2}$ tissue culture flask containing $5 \mathrm{~mL}$ media. HEK-Blue mTLR4 cells were grown to $70-80 \%$ confluency and passaged twice before use in

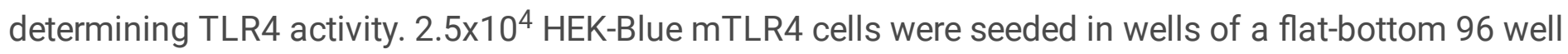
plate in medium containing $1 \mathrm{X}$ HEK-Blue Selection and $16 \%$ mouse serum taken from Panc02 tumor bearing mice treated with i.I. PBS or i.I. PV-10. Cultures were incubated for $18 \mathrm{hrs}$ and TLR4 activity was determined by the detection of secreted embryonic alkaline phosphatase (SEAP) using a spectrophotometer at $655 \mathrm{~nm}$.

\section{Flow cytometry}

Tissues were prepared for flow cytometric analysis as previously described [34]. Briefly, spleens were harvested under sterile conditions and were homogenized by forcing the tissue through $100 \mu \mathrm{m}$ cell strainers using the plunger from a syringe. Single-cell suspensions were prepared, and red blood cells were removed using red blood cell lysis buffer (BioLegend). The resulting suspension was passed through a $70 \mu \mathrm{m}$ cell strainer and washed once with PBS. Cells were resuspended in to a concentration of 0.5-1 $\times 10^{6}$ cells $/ \mathrm{mL}$ for flow cytometric analysis in FACS Buffer containing PBS, $5 \%$ fetal bovine serum, $1 \mathrm{mM}$ ethylenediaminetetraacetic acid (EDTA) (Sigma Aldrich), and $0.1 \%$ sodium azide (Sigma Aldrich). Cell viability was measured by staining cell suspensions with ZombieNIR (BioLegend). Prior to surface staining, cells were incubated with Fc Shield (TonboBiosciences) for murine specimens. For surface staining of murine specimens, cells were stained in FACS buffer with the following antibodies: CD3 (1452C11), CD4 (GK1.5), CD8 (53 - 6.7), CD11b (M1/70), Gr-1 (RB6-8C5) (all from BioLegend). Flurochromes that overlapped with the emission spectra of PV-10 were not used in this study. Cells were acquired by FACS Celesta (BD Biosciences), and the data were analyzed with FlowJo (Tree Star).

\section{Statistical Analysis}

Graphs were generated using GraphPad Prism software. Graphs represent mean values with SEM. P values were calculated in each respective figure where statistical tests were indicated. For mouse-tumor growth studies, tumor growth curves are shown as mean with SEM and significance was determined by 
2-way ANOVA and Sidak's multiple comparison's test. Mice were randomized after tumor cell implantation into respective treatment groups. For all other experiments, data were compared using either an unpaired 2-tailed Student's t-test corrected for multiple comparisons by a Bonferroni adjustment or Welch's correction. ${ }^{*}=\mathrm{P}<0.05 ;{ }^{* \star}=\mathrm{P}<0.01 ; * \star *=\mathrm{P}<0.001 ; * \star \star *=\mathrm{P}<0.0001 ; \mathrm{ns}=$ not significant.

\section{Declarations}

\section{Ethics approval and consent to participate}

Animal studies were carried out in compliance with ARRIVE guidelines. Mice were humanely euthanized by $\mathrm{CO}_{2}$ inhalation and cervical dislocation according to the American Veterinary Medical Association Guidelines. Mice were observed daily and were humanely euthanized if a solitary subcutaneous tumor exceeded $300 \mathrm{~mm}^{2}$ in area, evidence of ulceration, or mice showed signs referable to metastatic cancer. All animal experiments were approved by the Institutional Animal Care and Use Committee and performed in accordance with the U.S. Public Health Service policy and National Research Council guidelines.

\section{Consent for Publication}

Not Applicable.

\section{Competing Interests}

Not Applicable.

\section{Author Contributions}

P.I. Wrote the manuscript, prepared figures 1-7, performed experiments for figures 1, 2, 6, and performed data analysis and interpretation. J.M., A.M., S.A., M.B., J.B. S.K. performed experiments for Figures 3-7. J.E.M, A.A.S, and S.P-T. designed experiments, and provided data analysis and interpretation. S.P-T. provided critical revision of the article and final approval of the version to be published. All authors reviewed the manuscript.

\section{Acknowledgement}

This work was supported in part by the Flow Cytometry Core Facility of the $\mathrm{H}$. Lee Moffitt Cancer Center and Research Institute and in part by the Cancer Center Support Grant P30 CA076292. We also thank the Comparative Medicine Department of University of South Florida.

\section{Funding}

This work was supported by a sponsored research agreement from Provectus Inc. to the H Lee Moffitt Cancer Center and Research Institute. The funders had no role in study design, data collection and analysis, decision to publish, or preparation of the manuscript. 


\section{Data Availability Statement}

The datasets generated and/or analyzed during the current study are not publicly available because this study does not contain any large datasets that require the submission to a data repository. Data are available from the corresponding author on reasonable request.

\section{References}

1. Liu H, Innamarato PP, Kodumudi K, Weber A, Nemoto S, Robinson JL, Crago G, McCardle T, Royster E, Sarnaik AA et al: Intralesional rose bengal in melanoma elicits tumor immunity via activation of dendritic cells by the release of high mobility group box 1 . Oncotarget 2016.

2. Read TA, Smith A, Thomas J, David M, Foote M, Wagels M, Barbour A, Smithers BM: Intralesional PV10 for the treatment of in-transit melanoma metastases-Results of a prospective, non-randomized, single center study. J Surg Oncol 2018, 117(4):579-587.

3. Agarwala SS, Ross MI, Zager JS, Shirai K, Essner R, Smithers BM, Atkinson V, Wachter EA: Phase 1b study of PV-10 and anti-PD-1 in advanced cutaneous melanoma. Journal of Clinical Oncology 2019, 37(15_suppl):9559-9559.

4. Patel SP, Carter BW, Murthy R, Sheth R, Agarwala SS, Lu G, Redstone E, Balmes GC, Rider H, Rodrigues $D$ et al: Percutaneous hepatic injection of rose bengal disodium (PV-10) in metastatic uveal melanoma. Journal of Clinical Oncology 2020, 38(15_suppl):3143-3143.

5. Galluzzi L, Buque A, Kepp O, Zitvogel L, Kroemer G: Immunogenic cell death in cancer and infectious disease. Nature reviews Immunology 2017, 17(2):97-111.

6. Apetoh L, Ghiringhelli F, Tesniere A, Obeid M, Ortiz C, Criollo A, Mignot G, Maiuri MC, Ullrich E, Saulnier $\mathrm{P}$ et al: Toll-like receptor 4-dependent contribution of the immune system to anticancer chemotherapy and radiotherapy. Nature medicine 2007, 13(9):1050-1059.

7. Parker KH, Sinha P, Horn LA, Clements VK, Yang H, Li J, Tracey KJ, Ostrand-Rosenberg S: HMGB1 enhances immune suppression by facilitating the differentiation and suppressive activity of myeloidderived suppressor cells. Cancer research 2014, 74(20):5723-5733.

8. Parker $\mathrm{KH}$, Horn LA, Ostrand-Rosenberg S: High-mobility group box protein 1 promotes the survival of myeloid-derived suppressor cells by inducing autophagy. Journal of leukocyte biology 2016, 100(3):463-470.

9. Veglia F, Tyurin VA, Mohammadyani D, Blasi M, Duperret EK, Donthireddy L, Hashimoto A, Kapralov A, Amoscato A, Angelini R et al: Lipid bodies containing oxidatively truncated lipids block antigen crosspresentation by dendritic cells in cancer. Nature communications 2017, 8(1):2122.

10. Borges TJ, Wieten L, van Herwijnen MJ, Broere F, van der Zee R, Bonorino C, van Eden W: The antiinflammatory mechanisms of Hsp70. Frontiers in immunology 2012, 3:95.

11. Gastpar R, Gehrmann M, Bausero MA, Asea A, Gross C, Schroeder JA, Multhoff G: Heat shock protein 70 surface-positive tumor exosomes stimulate migratory and cytolytic activity of natural killer cells. Cancer research 2005, 65(12):5238-5247. 
12. Kim MP, Gallick GE: Gemcitabine resistance in pancreatic cancer: picking the key players. Clinical cancer research : an official journal of the American Association for Cancer Research 2008, 14(5):1284-1285.

13. Yarchoan M, Hopkins A, Jaffee EM: Tumor Mutational Burden and Response Rate to PD-1 Inhibition. New England Journal of Medicine 2017, 377(25):2500-2501.

14. Siegel RL, Miller KD, Jemal A: Cancer statistics, 2020. CA: A Cancer Journal for Clinicians 2020, 70(1):7-30.

15. Liau SS, Whang E: HMGA1 is a molecular determinant of chemoresistance to gemcitabine in pancreatic adenocarcinoma. Clinical cancer research : an official journal of the American Association for Cancer Research 2008, 14(5):1470-1477.

16. Sinn M, Bahra M, Liersch T, Gellert K, Messmann H, Bechstein W, Waldschmidt D, Jacobasch L, Wilhelm M, Rau BM et al: CONKO-005: Adjuvant Chemotherapy With Gemcitabine Plus Erlotinib Versus Gemcitabine Alone in Patients After RO Resection of Pancreatic Cancer: A Multicenter Randomized Phase III Trial. Journal of clinical oncology : official journal of the American Society of Clinical Oncology 2017, 35(29):3330-3337.

17. Kindler HL, Niedzwiecki D, Hollis D, Sutherland S, Schrag D, Hurwitz H, Innocenti F, Mulcahy MF, O'Reilly E, Wozniak TF et al: Gemcitabine plus bevacizumab compared with gemcitabine plus placebo in patients with advanced pancreatic cancer: phase III trial of the Cancer and Leukemia Group B (CALGB 80303). Journal of clinical oncology : official journal of the American Society of Clinical Oncology 2010, 28(22):3617-3622.

18. Von Hoff DD, Ervin T, Arena FP, Chiorean EG, Infante J, Moore M, Seay T, Tjulandin SA, Ma WW, Saleh $\mathrm{MN}$ et al: Increased survival in pancreatic cancer with nab-paclitaxel plus gemcitabine. The New England journal of medicine 2013, 369(18):1691-1703.

19. Beatty GL, Winograd R, Evans RA, Long KB, Luque SL, Lee JW, Clendenin C, Gladney WL, Knoblock DM, Guirnalda PD et al: Exclusion of T Cells From Pancreatic Carcinomas in Mice Is Regulated by Ly6C(low) F4/80(+) Extratumoral Macrophages. Gastroenterology 2015, 149(1):201-210.

20. Bayne LJ, Beatty GL, Jhala N, Clark CE, Rhim AD, Stanger BZ, Vonderheide RH: Tumor-derived granulocyte-macrophage colony-stimulating factor regulates myeloid inflammation and $\mathrm{T}$ cell immunity in pancreatic cancer. Cancer cell 2012, 21(6):822-835.

21. Jiang H, Liu X, Knolhoff BL, Hegde S, Lee KB, Jiang H, Fields RC, Pachter JA, Lim KH, DeNardo DG: Development of resistance to FAK inhibition in pancreatic cancer is linked to stromal depletion. Gut 2020, 69(1):122-132.

22. Jiang H, Hegde S, Knolhoff BL, Zhu Y, Herndon JM, Meyer MA, Nywening TM, Hawkins WG, Shapiro IM, Weaver DT et al: Targeting focal adhesion kinase renders pancreatic cancers responsive to checkpoint immunotherapy. Nature medicine 2016, 22(8):851-860.

23. Carstens JL, Correa de Sampaio P, Yang D, Barua S, Wang H, Rao A, Allison JP, LeBleu VS, Kalluri R: Spatial computation of intratumoral T cells correlates with survival of patients with pancreatic cancer. Nature communications 2017, 8:15095. 
24. Ghansah T, Vohra N, Kinney K, Weber A, Kodumudi K, Springett G, Sarnaik AA, Pilon-Thomas S: Dendritic cell immunotherapy combined with gemcitabine chemotherapy enhances survival in a murine model of pancreatic carcinoma. Cancer immunology, immunotherapy : Cl/ 2013, 62(6):10831091.

25. Di Caro G, Cortese N, Castino GF, Grizzi F, Gavazzi F, Ridolfi C, Capretti G, Mineri R, Todoric J, Zerbi A et al: Dual prognostic significance of tumour-associated macrophages in human pancreatic adenocarcinoma treated or untreated with chemotherapy. Gut 2016, 65(10):1710-1720.

26. Guerriero JL, Ditsworth D, Catanzaro JM, Sabino G, Furie MB, Kew RR, Crawford HC, Zong WX: DNA alkylating therapy induces tumor regression through an HMGB1-mediated activation of innate immunity. Journal of immunology 2011, 186(6):3517-3526.

27. Kang R, Zhang Q, Zeh HJ, 3rd, Lotze MT, Tang D: HMGB1 in cancer: good, bad, or both? Clinical cancer research : an official journal of the American Association for Cancer Research 2013, 19(15):4046-4057.

28. Tian J, Avalos AM, Mao SY, Chen B, Senthil K, Wu H, Parroche P, Drabic S, Golenbock D, Sirois C et al: Toll-like receptor 9-dependent activation by DNA-containing immune complexes is mediated by HMGB1 and RAGE. Nature immunology 2007, 8(5):487-496.

29. Nedjadi T, Evans A, Sheikh A, Barerra L, Al-Ghamdi S, Oldfield L, Greenhalf W, Neoptolemos JP, Costello E: S100A8 and S100A9 proteins form part of a paracrine feedback loop between pancreatic cancer cells and monocytes. BMC cancer 2018, 18(1):1255.

30. Tobin RP, Jordan KR, Kapoor P, Spongberg E, Davis D, Vorwald VM, Couts KL, Gao D, Smith DE, Borgers JSW et al: IL-6 and IL-8 Are Linked With Myeloid-Derived Suppressor Cell Accumulation and Correlate With Poor Clinical Outcomes in Melanoma Patients. Frontiers in oncology 2019, 9:1223.

31. Teijeira A, Garasa S, Gato M, Alfaro C, Migueliz I, Cirella A, de Andrea C, Ochoa MC, Otano I, Etxeberria I et al: CXCR1 and CXCR2 Chemokine Receptor Agonists Produced by Tumors Induce Neutrophil Extracellular Traps that Interfere with Immune Cytotoxicity. Immunity 2020, 52(5):856-871 e858.

32. Melisi D, Niu J, Chang Z, Xia Q, Peng B, Ishiyama S, Evans DB, Chiao PJ: Secreted interleukin-1alpha induces a metastatic phenotype in pancreatic cancer by sustaining a constitutive activation of nuclear factor-kappaB. Mol Cancer Res 2009, 7(5):624-633.

33. Xu D, Matsuo Y, Ma J, Koide S, Ochi N, Yasuda A, Funahashi H, Okada Y, Takeyama H: Cancer cellderived IL-1alpha promotes HGF secretion by stromal cells and enhances metastatic potential in pancreatic cancer cells. J Surg Oncol 2010, 102(5):469-477.

34. Innamarato P, Asby S, Morse J, Mackay A, Hall M, Kidd S, Nagle L, Sarnaik AA, Pilon-Thomas S: Intratumoral Activation of 41BB Costimulatory Signals Enhances CD8 T Cell Expansion and Modulates Tumor-Infiltrating Myeloid Cells. Journal of immunology 2020.

\section{Figures}



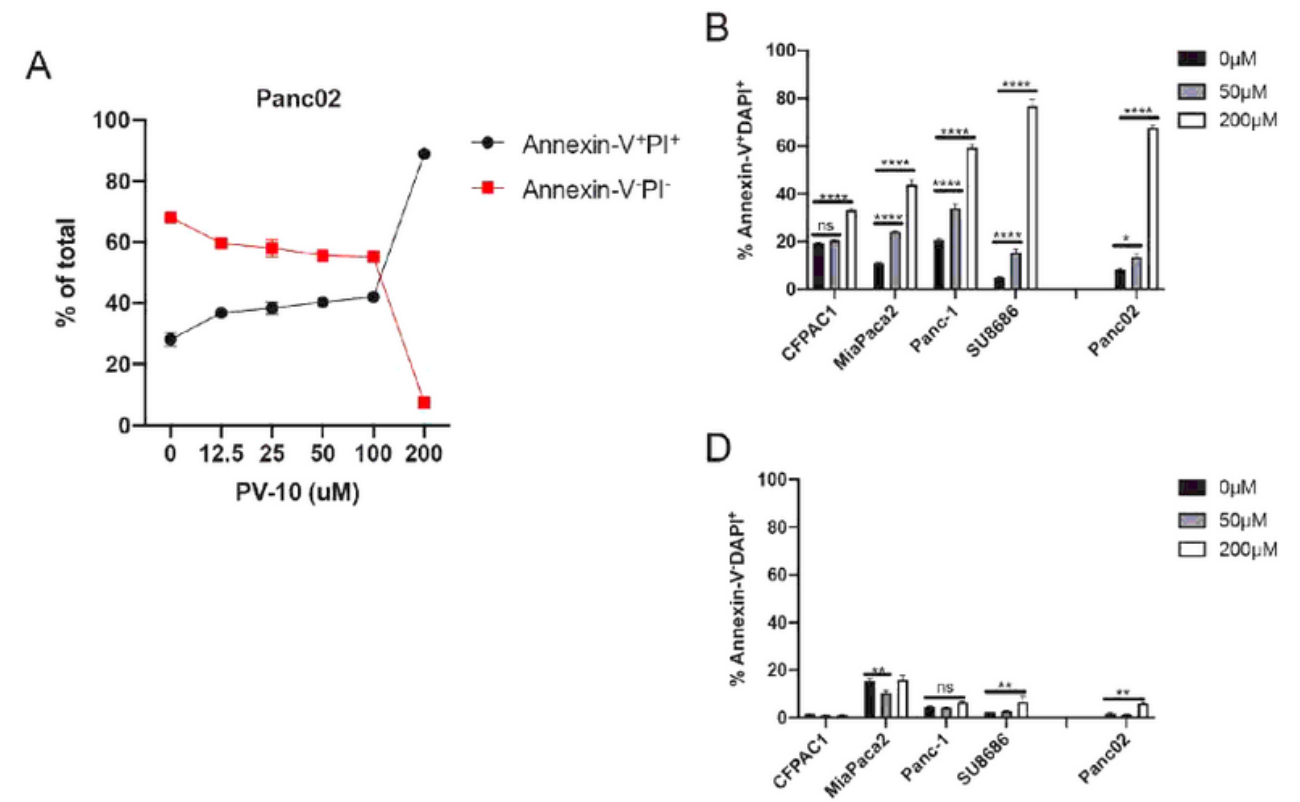
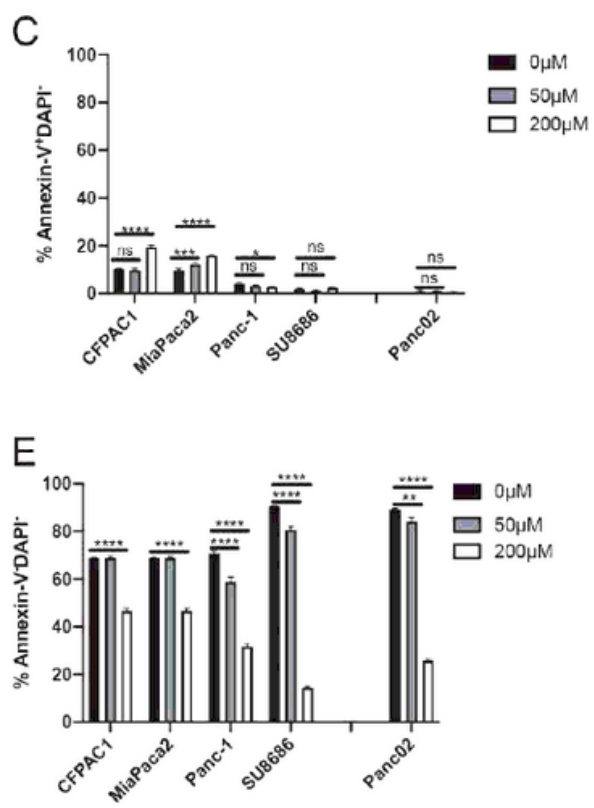

\section{Figure 1}

PV-10 kills mouse and human pancreatic tumor cells in vitro. (A-E) Mouse Panc02 tumor cells and human pancreatic tumor cell lines, CFPAC-1, MiaPaca2, Panc-1, and SU8686, were cultured overnight with the indicated concentrations of PV-10. (A) Percentage of Annexin-V+PI+ and Annexin-V-PI- Panc02 cells. Percentage of (B) Annexin-V+DAPI+, (C) Annexin-V+DAPI-, (D) Annexin-V-DAPI+, (E) Annexin-V-DAPImouse and human pancreatic tumor cells after PV-10 treatment. 
A

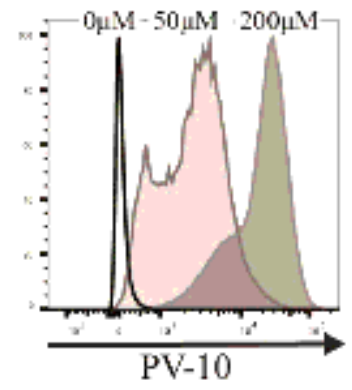

B

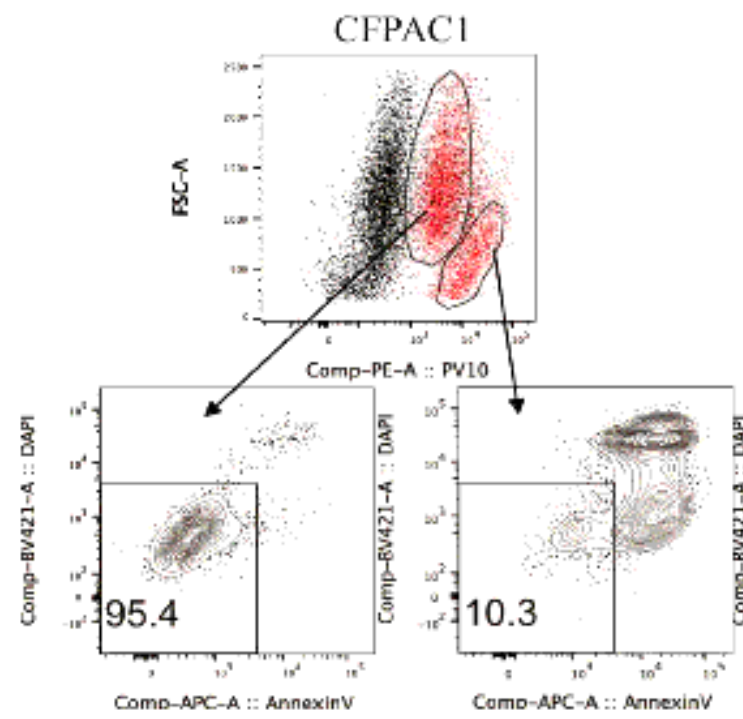

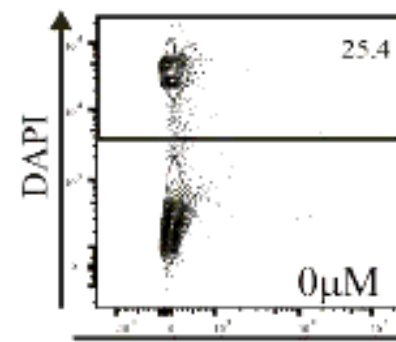

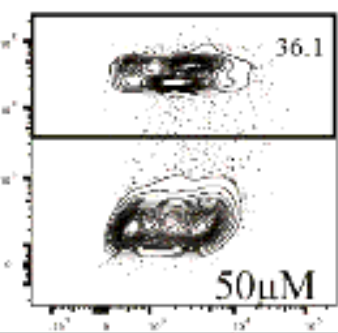

PV-10

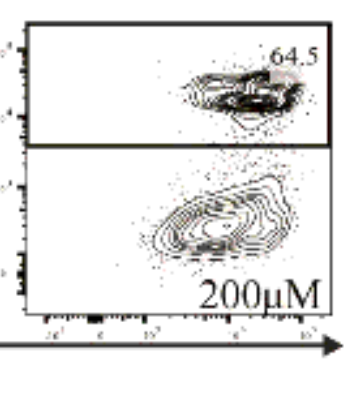

C
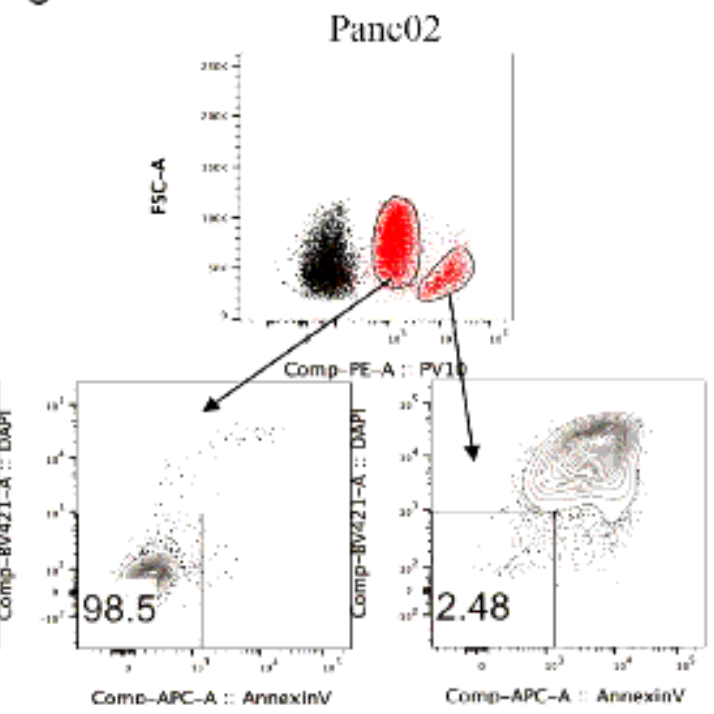

D

50 $\mu \mathrm{M}$ PV-10

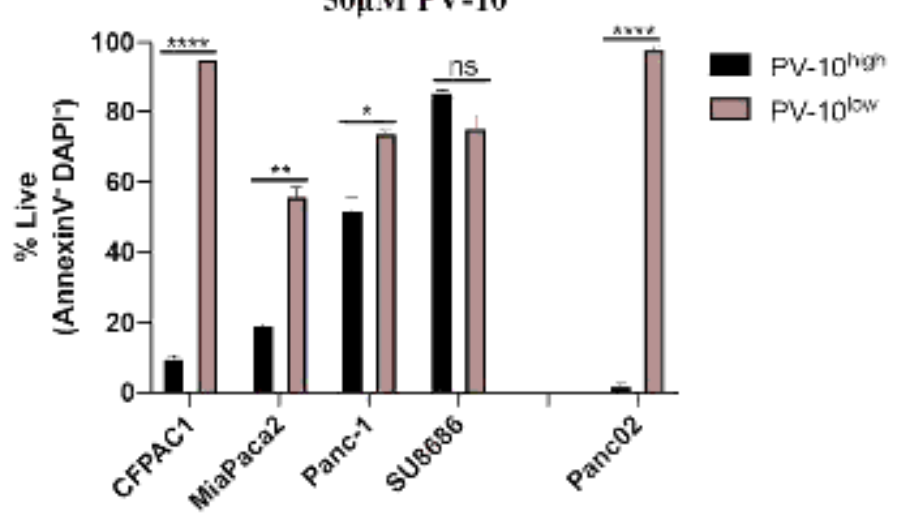

Figure 2

PV-10 saturation is an indicator of cell death (A) Staining intensity of PV-10 on Panc- 1 cells (histogram on far left) and the frequency of DAPI+ dead cells (dot plots to the right of the histogram). (B-C)

Representative dot plots showing increased cell death in (B) CFPAC-1 cells and (C) Panc02 cells with high PV-10 uptake (PV-10high) and low PV-10 uptake (PV-10low). Black population on dot plots are unstained, untreated control cells. Red populations are cells cultured with 50 $\mu \mathrm{M}$ PV-10. Arrows indicate the subgate of each respective population. (D) Percentage of live PV-10high/low cells treated with 50 $\mu \mathrm{M}$ PV-10. 
A HEKBlue-mTLR4 reporter

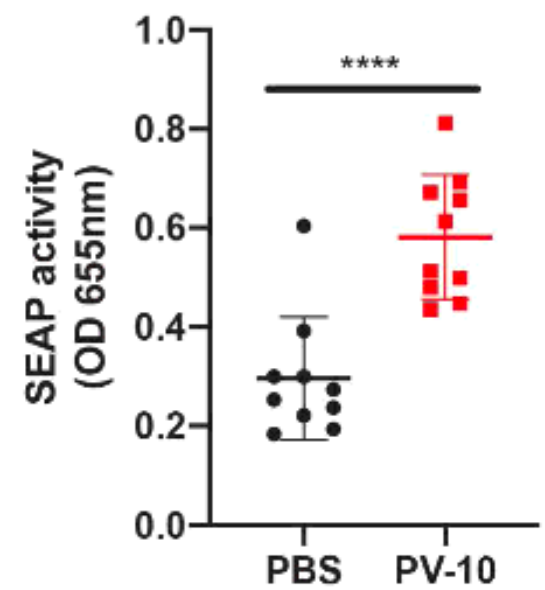

B

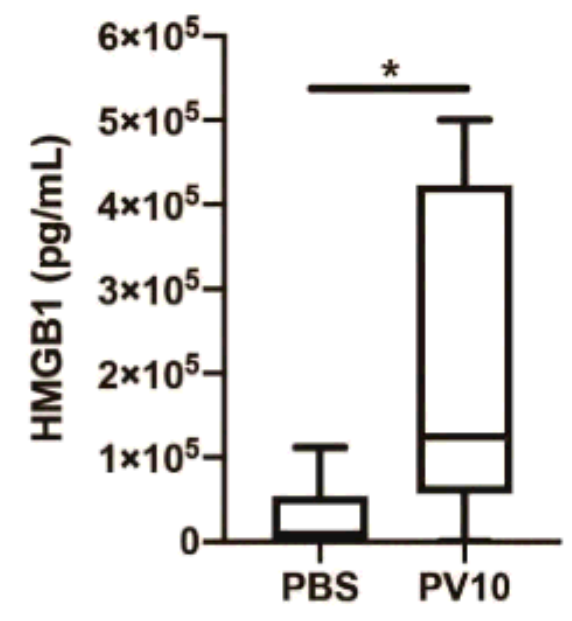

C
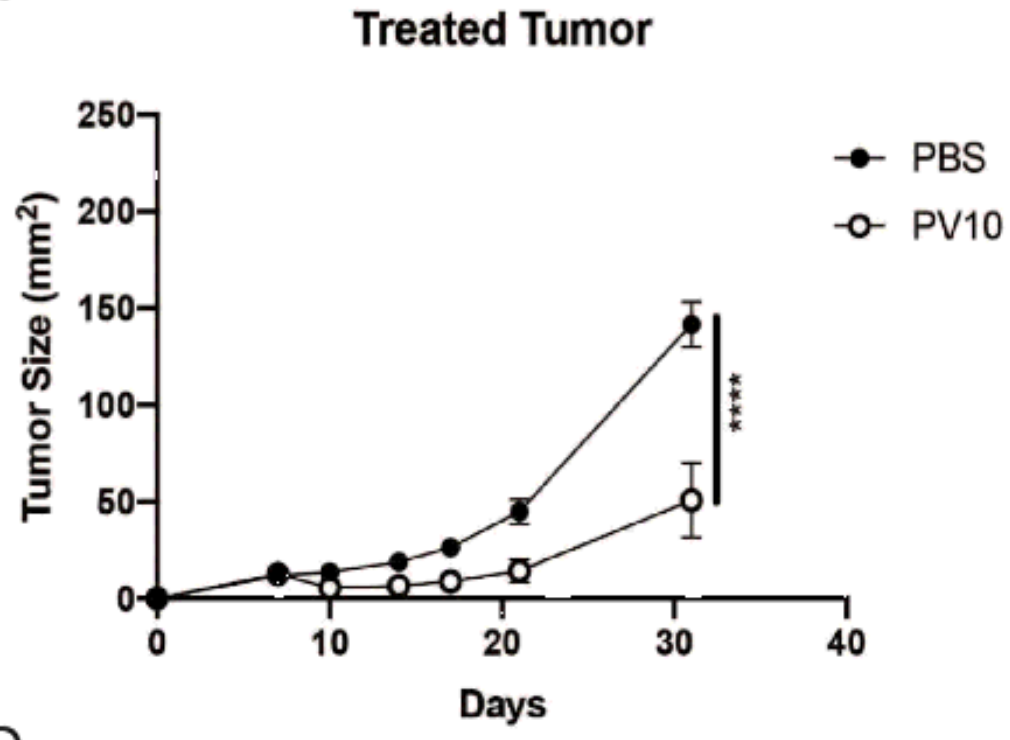

Bystander Tumor

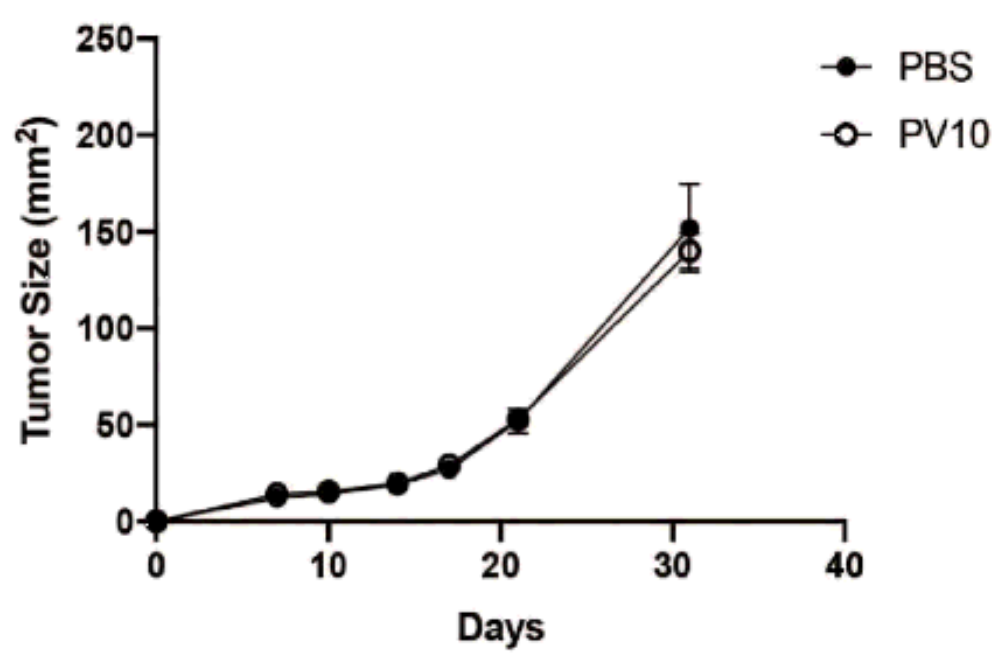

Figure 3

Effect of PV-10 against murine Panc02 tumors in vivo. (A) Serum collected from mice treated with i.I. PBS or i.I. PV-10 were collected $24 \mathrm{hrs}$ after treatment. Serum was cultured with HEKBlue-mTLR4 reporter cells overnight. (B) HMGB1 in the sera of mice treated with i.I. PBS or i.I. PV-10. (C) Tumor growth of treated tumors with i.I. PBS or i.I. PV-10. (D) Tumor growth of uninjected tumors implanted on the opposite flank of mice. 
A
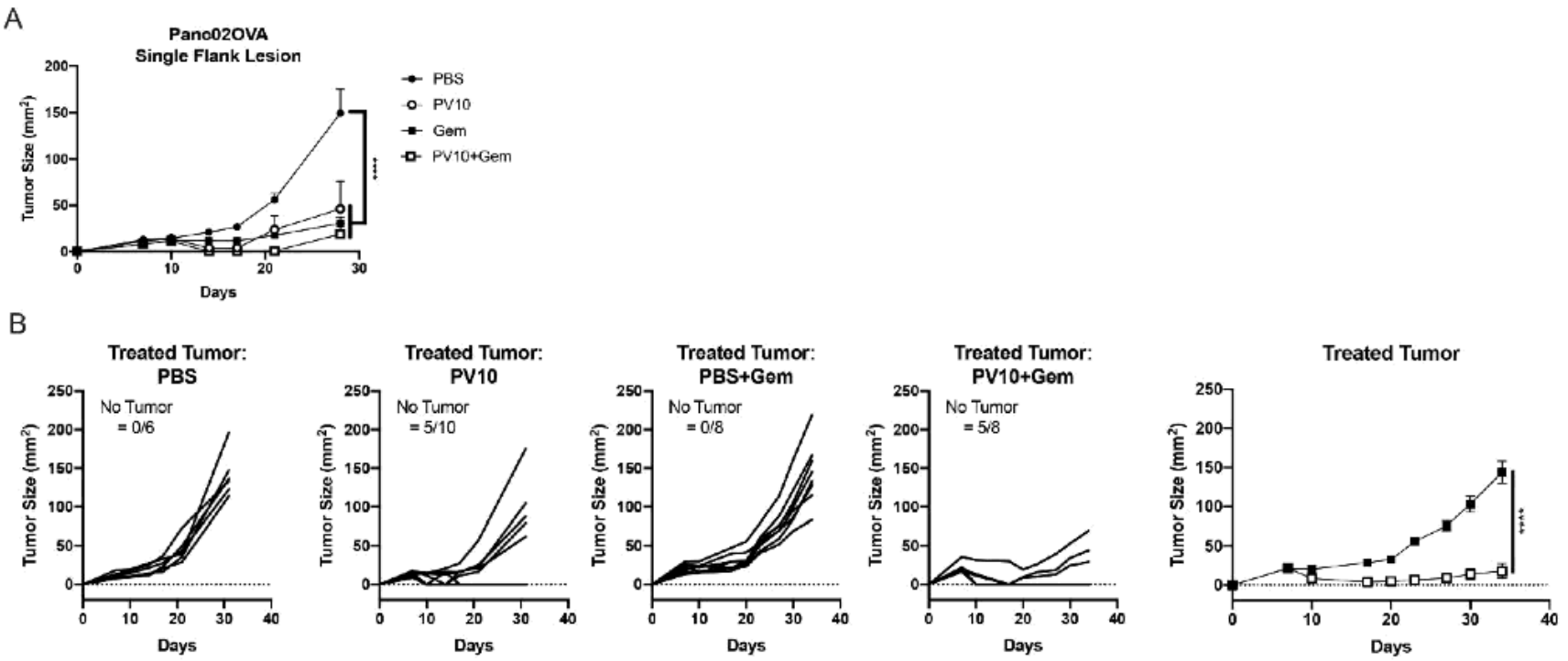

- PBS+Gem

-D. PV10+Gem
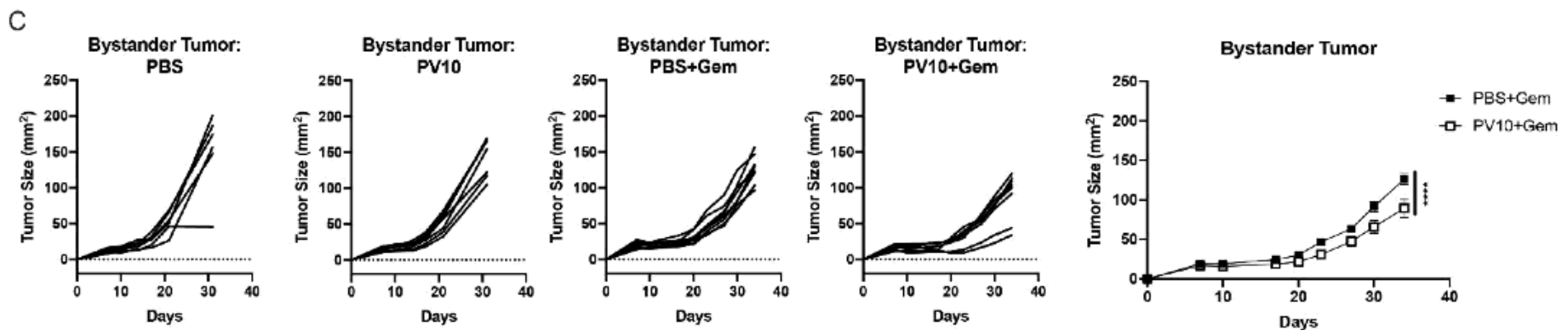

Figure 4

Panc020VA tumors are responsive to PV-10, gemcitabine combination therapy. (A) Tumor growth in mice bearing a single Panc020VA tumors treated with i.l. PV-10 \pm i.p. gemcitabine (Gem). (B-C) Tumor growth curves of individual mice with bilateral Panc020VA tumors. (B) Tumor growth curves for mice treated with i.I. PBS or i.I. PV-10 \pm i.p. Gem. Summary of growth among treated tumors with i.l. PBS or i.I. PV-10 in combination with Gem (far right). (C) Growth curves for uninjected contralateral tumors among individual mice. Summary of growth among contralateral tumors in mice that received i.I. treatment in the opposite flank in combination with i.p. Gem (far right). Sample size is indicated on each graph in (B). The rate of complete regression is also indicated on each graph in (B). 

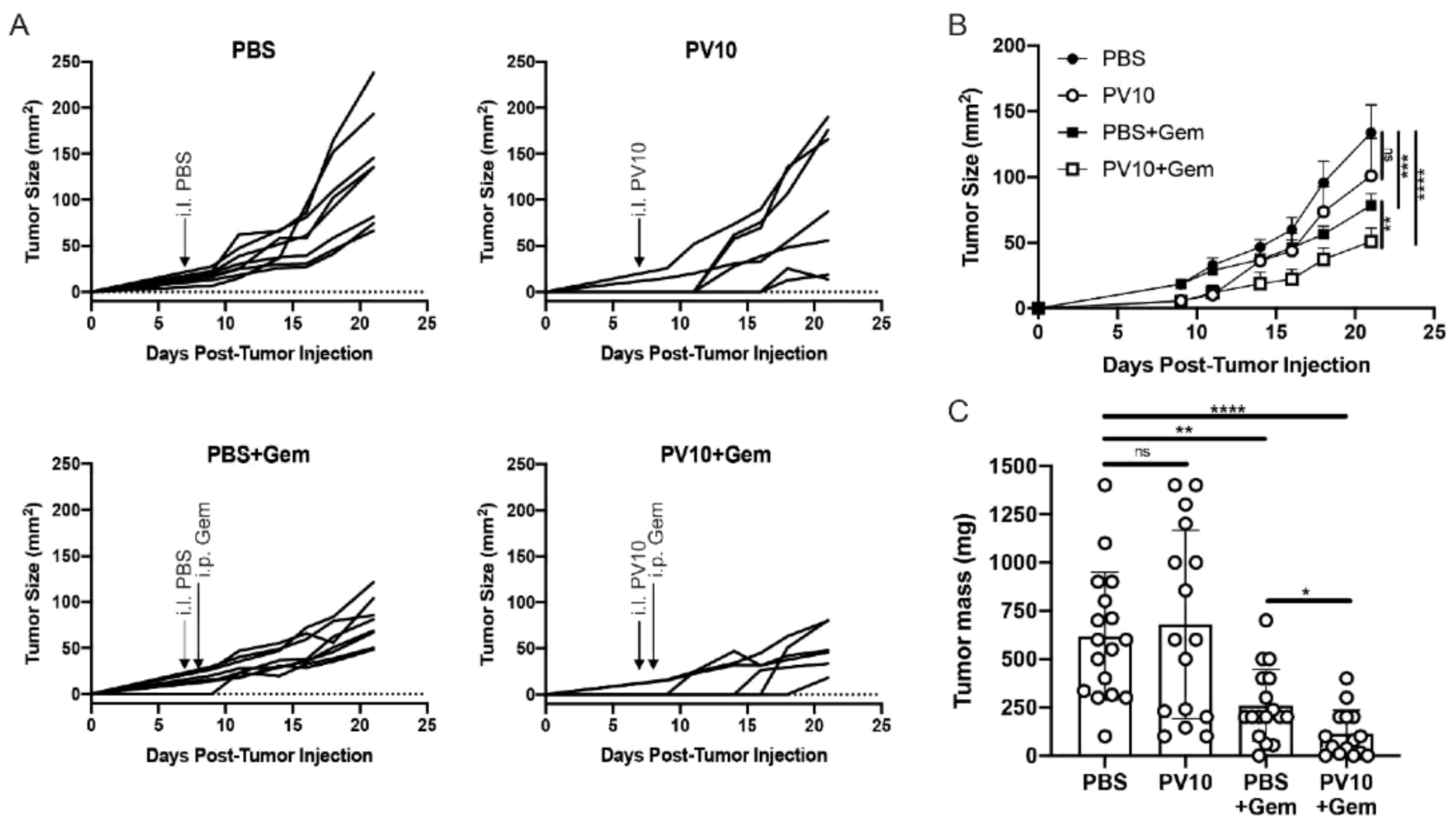

Figure 5

Combination therapy with PV-10 and gemcitabine induces tumor regression. (A) Individual tumor growth curves in mice that received i.I. PBS (top left), i.I. PV-10 (top right), i.I. PBS + i.p. Gem (bottom left), i.l. PV$10+$ i.p. Gem (bottom right). (B) Summary of tumor growth curves from (A) ( $n=6-8$ per group). Data are representative of 2 independent experiments (C) The mass of tumors at the termination of the experiment. Data are a compilation of 2 independent experiments. ( $n=16-17$ per group). 

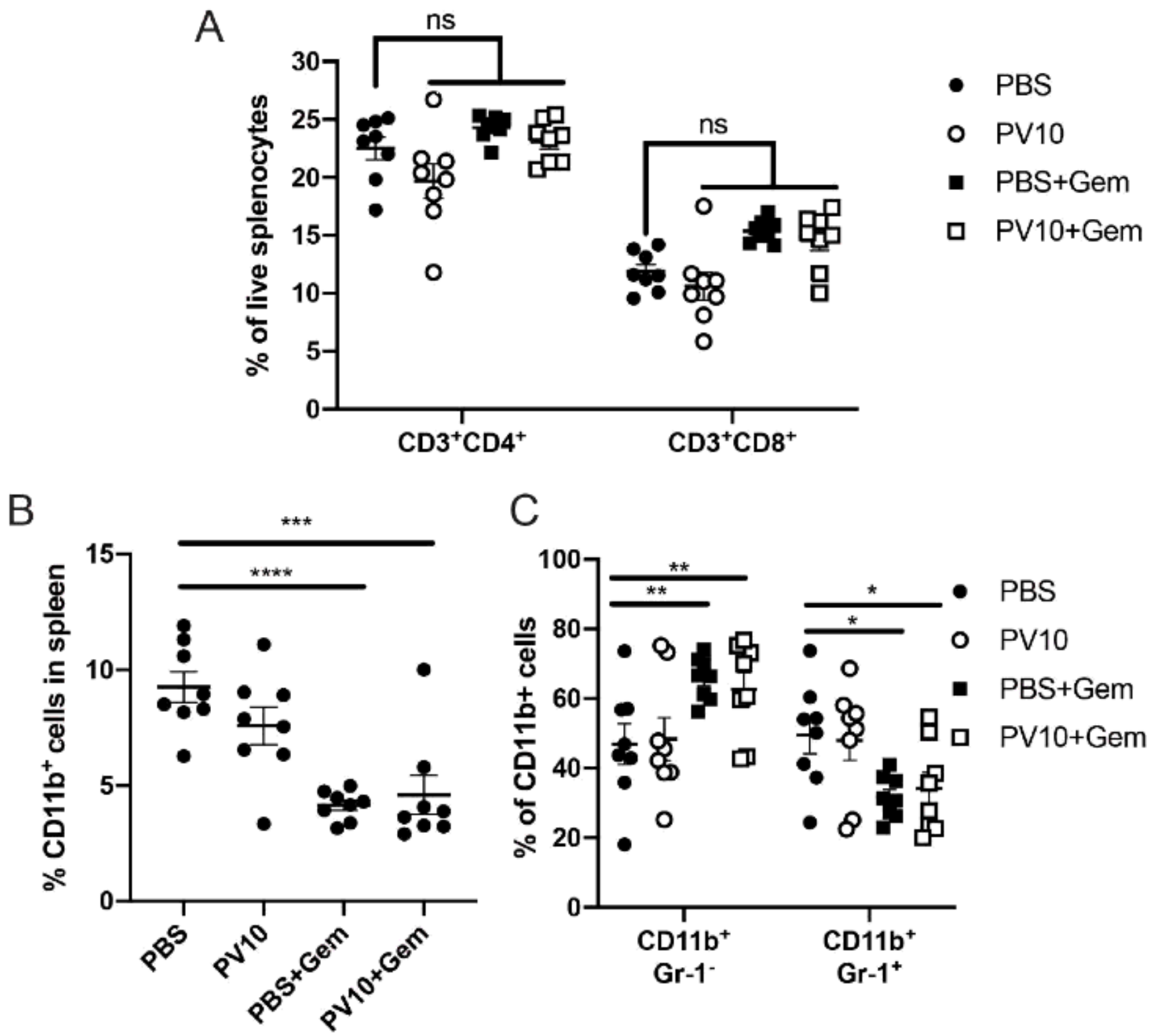

Figure 6

Gemcitabine reduces the frequency of peripheral myeloid cells. (A) The frequency of CD3+CD4+ and CD3+CD8+ T cells in spleens. (B) The frequency of CD11b+ myeloid cells in spleens is reduced after Gem treatment. (C) The percentage of cell subsets $C D 11 b+G r-1+/$ - among total myeloid cells in spleens. $(n=8$ per group). 

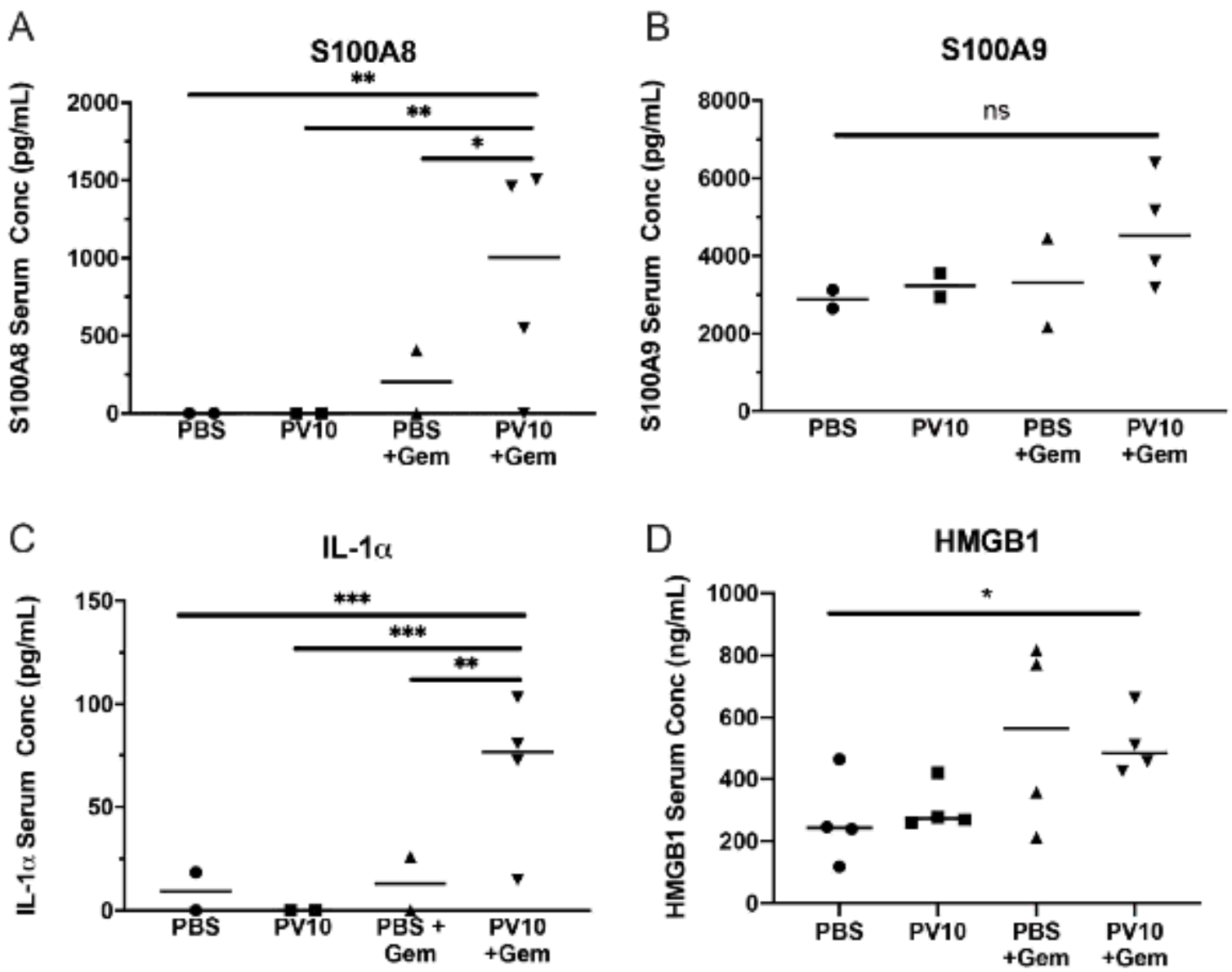

D

\section{HMGB1}

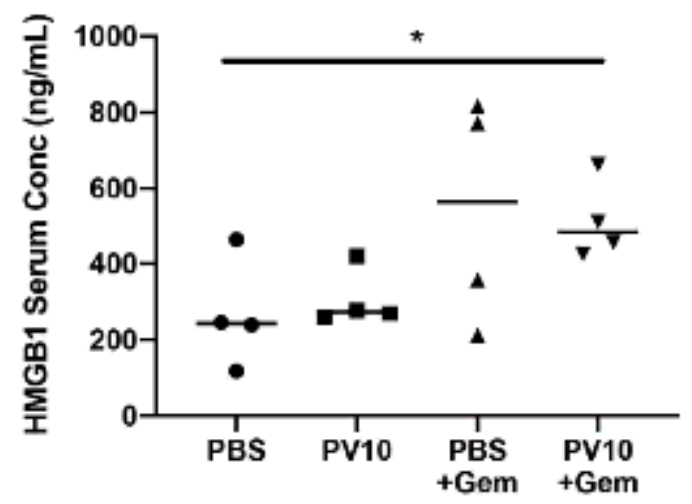

$\mathrm{E}$

HSP70

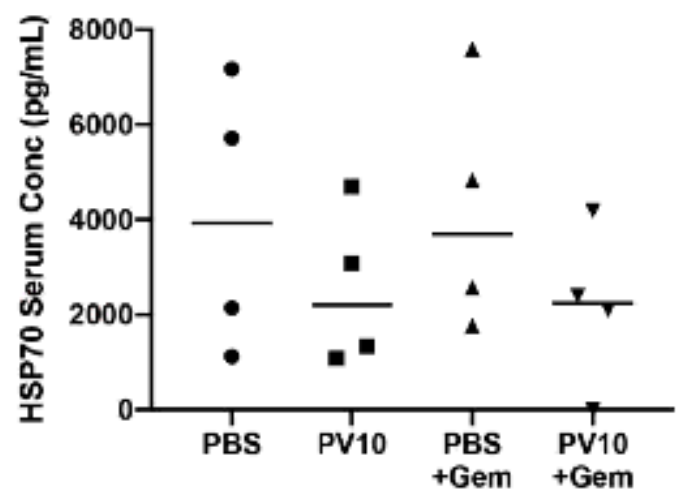

Figure 7

PV-10 and gemcitabine combination therapy increases the abundance of DAMPs in circulation. (A) S100A8, (B) S100A9, (C) IL-1a, (D) HMGB1, and (E) Hsp70 were measured in the sera of mice 9 days after the initiation of treatment. ( $n=2-4$ mice per group). 